TITLE:

\title{
Effects of side-chain hydroxyl groups on pyrolytic $\beta$-ether cleavage of phenolic lignin model dimer
}

\section{$\operatorname{AUTHOR}(\mathrm{S})$ :}

Kawamoto, Haruo; Horigoshi, Sunao; Saka, Shiro

\section{CITATION:}

Kawamoto, Haruo ... [et al]. Effects of side-chain hydroxyl groups on pyrolytic $\beta$-ether cleavage of phenolic lignin model dimer. Journal of Wood Science 2007, 53(3): 268-271

ISSUE DATE:

2007-06

URL:

http://hdl.handle.net/2433/240659

\section{RIGHT:}

This is a post-peer-review, pre-copyedit version of an article published in 'Journal of Wood Science'. The final authenticated version is available online at: https://doi.org/10.1007/s10086-006-0839-7.; The full-text file will be made open to the public on 1 June 2008 in accordance with publisher's 'Terms and Conditions for Self-Archiving'.; この論文は 出版社版でありません。引用の際には出版社版をご確認ご利用ください。; This is not the published version. Please cite only the published version. 
Title Page

Note

Title: Effects of side-chain hydroxyl groups on pyrolytic $\beta$-ether cleavage of phenolic lignin model dimer

\section{Authors:}

Haruo Kawamoto • Sunao Horigoshi • Shiro Saka

Haruo Kawamoto $(\bowtie) \cdot$ Sunao Horigoshi $\cdot$ Shiro Saka

Department of Socio-Environmental Energy Science, Graduate School of Energy Science, Kyoto University, Yoshida Hon-machi, Sakyo-ku, Kyoto 606-8501, Japan

Tel/Fax: +81-(0) 75-753-4737

E-mail:kawamoto@energy.kyoto-u.ac.jp

Keywords: lignin pyrolysis, model compound, $\beta$-ether cleavage, effect of hydroxyl group 
Abstract: Effects of side-chain hydroxyl groups on pyrolytic $\beta$-ether cleavage of phenolic model dimers were studied with various deoxygenated dimers under the pyrolysis conditions of $\mathrm{N}_{2} / 400^{\circ} \mathrm{C} / 1 \mathrm{~min}$. Although phenolic dimer with hydroxyl groups at $\mathrm{C}_{\alpha^{-}}$and $\mathrm{C}_{\gamma}$-positions was much more reactive than the corresponding non-phenolic type, deoxygenation at the $\mathrm{C}_{\gamma}$-position substantially reduced the reactivity up to the level of the non-phenolic type. These results are discussed with the cleavage mechanism via quinone methide intermediate formation, which is activated through intramolecular hydrogen bonds between $\mathrm{C}_{\alpha^{-}}$and $\mathrm{C}_{\gamma}$ - hydroxyl groups. 


\section{Introduction}

Betha-ether linkage is an important structure in pyrolytic depolymerization of lignin, because this structure, the most abundant structure in lignin macromolecule, is reported to be cleaved effectively under pyrolysis conditions. ${ }^{1-3}$ Model compound study indicated that phenolic $\beta$-ether structure is more reactive than the non-phenolic type. ${ }^{2,3}$ Although the content of the phenolic structure is small in natural lignin, ${ }^{4}$ chain depolymerization is expected via successive formation of the new phenolic structure through cleaving the phenolic end structure. Thus, the activation mechanism in the phenolic $\beta$-ether structure is especially important to understand and control the depolymerization behavior in lignin pyrolysis.

Several mechanisms including ionic (heterolytic) and homolytic mechanisms are proposed for the pyrolytic cleavage of the $\beta$-ether linkage. As for the ionic mechanism, retro-ene and oxirane mechanisms are proposed. Klein and Virk ${ }^{5}$ proposed a 6-centered retro-ene mechanism through kinetic analysis of the formation behavior of styrene and phenol from phenethyl phenyl ether, which has no substituent groups at the aromatic ring and side-chain. Kislitsyn et al. $^{6}$ proposed an oxirane mechanism, in which $\beta$-ether is heterolytically cleaved by the attack of $\mathrm{C}_{\alpha^{-}}$or $\mathrm{C}_{\gamma}$-hydroxyl group to the $\beta$-carbon. Brežný et al. $^{2}$ reported the several pyrolysis products from guaiacylglycerol- $\beta$-guaiacyl ether and explained their formation by oxirane mechanism. As for homolytic mechanism, homolytic $\mathrm{C}_{\beta}-\mathrm{O}$ session via benzyl radical is proposed for the pyrolytic cleavage of phenethyl phenyl ether. ${ }^{7,8}$ Evans et al. $^{9}$ also proposed a modified homolytic mechanism assisted by $\mathrm{C}_{\alpha}$-hydroxyl group. However, these mechanisms are still controversial because of the lack of their supporting proofs.

In solvent or under steam conditions, homolytic $\mathrm{C}_{\beta}-\mathrm{O}$ cleavage via quinone methide intermediate is proposed by several groups. Sano's group ${ }^{10-12}$ reported the several 
condensation products as a proof of the quinone methide intermediate involved in the $\beta$-ether cleavage in pulping reaction in water-organic solvent mixture. Tanahashi et al. ${ }^{13}$ also proposed a similar homolytic mechanism under stream explosion conditions. Kawamoto et al. ${ }^{14}$ reported that the homolytic mechanism via quinone methide intermediate is also important under pyrolysis conditions without solvent and steam environment, from the relationship between reactivity and Hammett $\sigma_{p}$ or $\triangle \mathrm{BDE}$ (bond dissociation energy) in pyrolysis of $\alpha$ - and $\alpha, \beta$-diether types of model dimers with variously $p$-substituted $\mathrm{C}_{\alpha}$-phenyloxy groups. They also explained that higher reactivity of the phenolic form is attributed to the easier formation of the quinone methide intermediate than the non-phenolic one.

In this paper, role of $\mathrm{C}_{\alpha}$ - and $\mathrm{C}_{\gamma}$-hydroxyl groups on the pyrolytic $\beta$-ether cleavage of phenolic model dimer studied with various deoxygenated dimers at $400^{\circ} \mathrm{C}$ are presented.

\section{Materials and method}

Pyrolysis products were separated by preparative thin layer chromatography (TLC) on silica gel plate (Kieselgel $60 \mathrm{~F}_{254}$, Merk). High performance liquid chromatography (HPLC) was carried out with Shimadzu LC-10A under the following chromatographic conditions (column: STR ODS-II, flow rate: $0.7 \mathrm{ml} / \mathrm{min}$, eluent: $\mathrm{MeOH} / \mathrm{H}_{2} \mathrm{O}=30 / 70 \rightarrow 100 / 0$ $(0 \rightarrow 40 \mathrm{~min}), 100 / 0(10 \mathrm{~min})$, detector: $\mathrm{UV}_{254 \mathrm{~nm}}$, temperature: $\left.40^{\circ} \mathrm{C}\right)$. Proton magnetic resonance $\left({ }^{1} \mathrm{H}-\mathrm{NMR}\right)$ spectra were recorded in $\mathrm{CDCl}_{3}$ with Varian $\mathrm{AC}-300(300 \mathrm{MHz})$ spectrometer with tetramethylsilane (TMS) as an internal standard.

\section{Materials}

Model compounds used in this study are shown in Fig. 1. Results of the 
1-(4-hydroxy-3-methoxyphenyl)-2-(2-methoxyphenoxy)-1,3-propanediol

(guaicylglycerol- $\beta$-guaicyl

ether,

1)

and

1-(3,4-dimethoxyphenyl)-2-(2-methoxyphenoxy)-1,3-propanediol

(veratrylglycerol- $\beta$-guaiacyl ether, 5) are already described in the previous paper. ${ }^{3}$ So, deoxygenated model dimers 2-4 were prepared. $\alpha$-Deoxy dimer, 3-(4-hydroxy-3-methoxyphenyl)-2-(2-methoxyphenoxy)-1-propanol (2) was prepared by the modified procedure described by Freudenberg and Müller ${ }^{15}$ and identified by ${ }^{1} \mathrm{H}-\mathrm{NMR}$ analysis of the acetate compared with the spectrum already reported. ${ }^{16} \gamma$-Deoxy dimer, 1-(4-hydroxy-3-methoxyphenyl)-2-(2-methoxyphenoxy)-1-propanol (3) was prepared by the method described by Dimmel and Shepard. ${ }^{17} \quad \alpha, \gamma$-Dideoxy dimer, 1-(4-hydroxy-3-methoxyphenyl)-2-(2-methoxyphenoxy)propane (dihydroeugenol- $\beta$-guaiacyl ether, 4) was prepared according to the procedure described by McKague et al. ${ }^{18}$ from $\beta$-bromodihydroeugenol and guaiacol and identified with the ${ }^{1} \mathrm{H}-\mathrm{NMR}$ spectrum of the acetate compared with the spectrum already reported. ${ }^{19}$

Pyrolysis and product analysis

Pyrolysis of lignin model compound was conducted with the experimental setup as previously reported, ${ }^{3}$ which contains a round flask (volume: $20 \mathrm{ml}$ ) with a glass tube $(120 \mathrm{~mm}$ long and $14 \mathrm{~mm}$ in diameter) for trapping the volatile products and a nitrogen bag attached through a tree-way tap. Model dimer $(10 \mathrm{mg})$ was placed at the bottom of the flask by evaporating the solution in $\mathrm{MeOH}(2.0 \mathrm{ml})$, and the air in the system was replaced with nitrogen. Pyrolysis was conducted by inserting the flask in a salt bath $\left(\mathrm{KNO}_{3} / \mathrm{NaNO}_{3}=\right.$ $1 / 1, \mathrm{w} / \mathrm{w}$ ) preheated at $400^{\circ} \mathrm{C}$ for $1 \mathrm{~min}$. After pyrolysis, the flask was immediately cooled with air flow for 30 min and cold water, and then the reaction system was opened to release the gaseous products. The reaction mixture was extracted with THF $(5.0 \mathrm{ml})$ twice and the 
combined solution was evaporated in vacuo to give THF-soluble fraction. Products and the model dimer recovered in the THF-soluble fraction were quantified by HPLC with p-dibromoboenzene as an internal standard. Coniferyl alcohol, isoeugenol and guaiacol were also confirmed by the ${ }^{1} \mathrm{H}-\mathrm{NMR}$ spectra of the isolated compounds compared with those of the authentic compounds.

\section{Results and discussion}

Figure 2 summarizes the HPLC chromatograms of the pyrolysis mixtures obtained from deoxygenated model dimers 2-4 under the pyrolysis conditions $\left(\mathrm{N}_{2} / 400^{\circ} \mathrm{C} / 1 \mathrm{~min}\right)$. All model dimers gave similar types of the products including 1-phenylpropnenes and guaiacol. Guaiacol is a product which indicates the $\beta$-ether cleavage.

Table 1 summarizes the product yields from dimers 2-4 with reacted model dimer (\%) calculated from the model dimer recovery. The results of dimer $\mathbf{1}$ with hydroxyl groups at the $\mathrm{C}_{\alpha}$ - and $\mathrm{C}_{\gamma}$-positions and its non-phenolic type $\mathbf{5}$ are also included, both of which are already reported in the previous paper. ${ }^{3}$ Except for the vinyl ether formation, product types are similar between deoxygenated dimers 2-4 and dimers $\mathbf{1}$ and $\mathbf{5 .}$ However, the yields are quite different depending on the structure. Although phenolic dimer $\mathbf{1}$ is very reactive as indicated by the reacted model dimer (50.3\%) and the product yields [guaiacol (50.1\%) and 1-phenylpropene (coniferyl alcohol) (30.4\%)], the reactivities of the deoxygenated dimers 2-4 are comparatively very low [reacted model dimers (4.3-7.9\%), guaiacol (3.5-4.1\%) and 1-phenylpropene (1.1-1.7\%)]. Interestingly, these reactivities are rather similar to that of the non-phenolic dimer 5 [reacted model dimers (8.4\%), guaiacol (3.1\%) and 1-phenylpropene (4-O-methyl coniferyl alcohol) (0.5\%)].

These results are very interesting in terms of the cleavage mechanism. As shown in Fig. 3, two types of the reactions take place in the pyrolysis of $\beta$-ether types of model dimer, 
which include the $\mathrm{C}_{\beta}-\mathrm{O}$ cleavage (a) and $\mathrm{C}_{\gamma}$-elimination to form vinyl ether $(\mathbf{b}){ }^{3}$ 1-Phenylpropenes are the products from pathway a. Phenolic vinyl ether structure was very reactive under the present pyrolysis conditions to form the $\beta$-ether cleaved products. ${ }^{3}$ So, there is a little information about the reaction pathway $\mathbf{b}$ from the present results. However, low yields of the 1-phenylpropnen derivatives as well as guaiacol from deoxygenated dimers 2-4 indicate that $\beta$-ether cleavage via pathway a substantially suppressed in the deoxygenated structures to the level of the non-phenolic dimer $\mathbf{5 .}$

As already described, homolytic $\mathrm{C}_{\beta}-\mathrm{O}$ cleavage is substantially activated in the quinone methide intermediate (Fig. 4), ${ }^{14}$ probably due to lowering the bond dissociation energy of the $\mathrm{C}_{\beta}-\mathrm{O}$ bond in quinone methide form. Lower bond dissociation energy in quinone methide form is calculated by Russian scientist. ${ }^{20}$ Therefore, formation of the quinone methide intermediate is critical for the higher $\beta$-ether cleavage reactivity of the phenolic model dimer 1. $\mathrm{C}_{\alpha}$-Hydroxyl group and $p$-hydroxylated aromatic ring are the important components in quinone methide formation from lignin related compound in solvent. However, low reactivity of the $\mathrm{C}_{\gamma}$-deoxygenated dimer $\mathbf{3}$, which also has these components, indicates that quinone methide is not formed effectively during pyrolysis of dimer 3. This leads to a very interesting conclusion that the $\mathrm{C}_{\gamma}$-hydroxyl group plays an important role in quinone methide formation under pyrolysis conditions.

Unlike the reaction in solvent, pyrolysis conditions do not include the solvent stabilizing effects of polar or ionic species. Low reactivity of dimer $\mathbf{3}$ may related to this characteristic nature of pyrolysis. Different pyrolytic mechanisms are also indicated between dimers $\mathbf{1}$ and $\mathbf{3}$ by our proceeding studies. ${ }^{21}$ Although further study is necessary to confirm the hypothesis, high reactivity of dimer $\mathbf{1}$ for quinone methide formation is explainable with the stable cyclic transition state (Fig. 4) with hydrogen bonds between $\mathrm{C}_{\alpha^{-}}$ and $\mathrm{C}_{\gamma}$-hydroxyl groups. Cyclic transition state mechanism is proposed for pyrolysis of $\beta$-hydroxy ketones, ${ }^{22,}{ }^{23} \beta$-hydroxy olefins ${ }^{24}$ and $\beta, \gamma$-unsaturated acids. ${ }^{25,26}$ For example, 
thermal retrograde aldol condensation of some $\beta$-hydroxy ketone is reported to proceed much faster in the structure which can form a cyclic transition state than other similar $\beta$-hydroxy ketones. ${ }^{22}$ The $\beta$-ether linkage in $\mathrm{C}_{\gamma}$-deoxygenated dimer $\mathbf{3}$, which can not form these hydrogen bonds, is considered to proceed in direct homolytic $\mathrm{C}_{\beta}-\mathrm{O}$ cleavage as like model dimers 2, 4 and 5 . 


\section{Acknowledgements}

This research was supported by a Grant-in-Aid for Scientific Research (C)(2)(No. 11660164, 1999.4-2000.3) and 21 ${ }^{\text {st }}$ COE program "Establishment of Sustainable Energy System” from Ministry of Education, Culture, Sports, Science and Technology, Japan. 


\section{References}

1. Haw JF, Schultz TP (1985) Carbon-13 CP/MAS NMR and FT-IR study of low-temperature lignin pyrolysis. Holzforschung 39: 289-296.

2. Brežný R, Mihálov V, Kováčik V (1983) Low temperature thermolysis of lignins. I. Reactions of $\beta-O-4$ model compounds. Holzforschung 37: 199-204.

3. Kawamoto H, Horigoshi S, Saka S Pyrolysis reactions of various lignin model dimers. J.W.S in press.

4. Whiting P, Goring D A I (1982) Phenolic hydroxy analysis of lignin by pyrolytic gas chromatography. Paperi ja Puu (10): 592-595

5. Klein M T, Virk P S (1983) Model pathways in lignin thermolysis. 1. Phenethyl phenyl ether. Ind. Eng. Chem. Fundam. 22: 35-45

6. Kislitsyn A N, Rodionova Z M, Savinykh V I (1971) Study of thermal decomposition of monophenylether of ethylene glycol. Khim. Drev.: 131-136

7. Autrey S T, Alnajjar M S, Nelson D A, Franz J A (1991) Absolute rate constants for $\beta$-Scission reaction of the 1-phenyl-2-phenoxypropyl radical: A model for radical reactions of lignin. J. Org. Chem. 56: 2197-2202

8. Britt P F, Buchanan III A C, Thomas K B, Lee S-K (1995) Pyrolysis mechanisms of lignin: surface-immobilized model compound investigation of acid-catalyzed and free-radical reaction pathways. J. Anal. Appl. Pyrolysis 33: 1-19

9. Evans R J, Milne T A, Soltys M N (1986) Direct mass-spectrometoric studies of the pyrolysis of carbonaceous fuels III. Primary pyrolysis of lignin. J. Anal. Appl. Pyrolysis 9: $207-236$

10. Sano Y (1975) Hydrolysis of lignin with dioxane and water XV. Hydrolysis of 1-guaiacyl-2-guaiacoxy-1-propene-3-ol and guaiacylglycerol- $\beta$-guaiacyl ether. Mokuzai Gakkaishi 21(9): 508-519. 
11. Sano Y (1989) Reactivity of $\beta-O-4$ linkages in lignin during solvolysis pulping. Degradation of $\beta-O-4$ lignin model compounds. Mokuzai Gakkaishi 35(9): 813-819.

12. Kishimoto T, Sano Y (2002) Delignification mechanism during high-boiling solvent pulping. Part 2. Homolysis of guaiacylglycerol- $\beta$-guaiacyl ether. Holzforschung 56(6): 623-631.

13. Tanahashi M,Karina M, Tamabuchi K, Higuchi M (1989) Degradation mechanism of lignin accompanying steam explosions I. Degradation products of lignin and $\beta-O-4$ lignin substructure model dimmers. Mokuzai Gakkaishi 35 (2): 135-143

14. Kawamoto H, Nakamura T, Saka S (2004) Mechanism of the pyrolytic cleavage of ether structures in lignin. Proceedings of the $49^{\text {th }}$ Lignin Symposium, Tsukuba, Nov. 18, 19, 85-88.

15. Freudenberg K, Müller H G (1953) Synthetische Versuche im Zusammenhang mit dem Lignin. Liebigs Ann. Chem. 584: 40-53

16. Johanson B, Miksche G E (1972) Über die Benzyl-arylätherbindung im Lignin II. Versuche an Modellen. Acta Chem. Scand. 26: 289-308

17. Dimmel D R, Shepard D (1982) Synthesis of lignin model dimers by novel techniques. J Wood Chem. Technol. 2(3): 297-315

18. McKague A B, Kang G J, Reeve D W (1993) Reaction of a lignin model dimer with chlorine and chlorine dioxide. Horzforschung 47: 497-500

19. Sundholm F (1968) On the synthesis of guaiacyl ethers of 1-veratryl-2-propanol and 1-guaiacyl-2-propanol. Acta Chem. Scand. 22(3): 854-858

20. Ponomarev DA (1997) Formation of quinone methides: An alternative pathway to thermal degradation of some $\beta$-O-4-ether as compounds modeling lignin. Russian J. Appl. Chem. 70(5) 824-826.

21. Kawamoto H, Ryoritani M, Saka S, unpublished data.

22. Smith GG, Yates BL (1965) Pyrolysis studies. XV. Thermal retrograde aldol condensation 
of $\beta$-hydroxy ketones. J. Chem. Soc.: 2067-2078.

23. Mole T (1960) Thermal retro-aldol reaction. Chemistry \& Industry (London), 1164-1165.

24. Smith GG, Taylor R (1961) Kinetic evidence for the mechanism of pyrolysis of $\beta$-hydroxyolefines. Chemistry \& Industry (London), 949.

25. Arnord RT, Elmer OC, Dodson RM (1950) Thermal decarboxylation of unsaturated acids. J. Am. Chem. Soc. 72: 4359-4361.

26. Smith GG, Blau SE (1964) Decarboxylation. I. Kinetic study of the vapor phase thermal decarboxylation of 3-butenoic acid. J. Phys. Chem. 68(5): 1231-1234. 
Table 1. Yields of some degradation products from dimers $\mathbf{1 - 5}$ under the pyrolysis conditions $\left(\mathrm{N}_{2} / 400^{\circ} \mathrm{C} / 1 \mathrm{~min}\right)$.

\begin{tabular}{|c|c|c|c|c|c|c|c|}
\hline & \multirow{2}{*}{$\mathrm{R}$} & \multirow{2}{*}{$\mathrm{X}$} & \multirow{2}{*}{$\mathrm{Y}$} & \multirow{2}{*}{$\begin{array}{l}\text { Model compound } \\
\text { reacted }(\%)\end{array}$} & \multicolumn{3}{|c|}{ Products (\%) } \\
\hline & & & & & Guaiacol & 1-Phenylpropene & Vinyl ether \\
\hline 1 & $\mathrm{H}$ & $\mathrm{OH}$ & $\mathrm{OH}$ & 50.3 & 50.1 & $30.4^{1)}$ & Trace ${ }^{4)}$ \\
\hline 2 & $\mathrm{H}$ & $\mathrm{OH}$ & $\mathrm{H}$ & 7.9 & 3.5 & $1.1^{2)}$ & nd $^{5)}$ \\
\hline 3 & $\mathrm{H}$ & $\mathrm{H}$ & $\mathrm{OH}$ & 4.3 & 4.1 & $1.5^{1)}$ & nd \\
\hline 4 & $\mathrm{H}$ & $\mathrm{H}$ & $\mathrm{H}$ & 6.7 & 3.5 & $1.7^{2)}$ & nd \\
\hline 5 & $\mathrm{CH}_{3}$ & $\mathrm{OH}$ & $\mathrm{OH}$ & 8.4 & 3.1 & $0.5^{3)}$ & $0.6^{6)}$ \\
\hline
\end{tabular}

1) Coniferyl alcohol (6), 2) isoeugenol (8), 3) 4-O-methyl coniferyl alcohol (9),

4) 2-(2-methoxyphenoxy)-1-(4-hydroxy-3-methoxyphenyl)ethene (10), 5) not detected,

6) 2-(2-methoxyphenoxy)-1-(3,4-dimethoxyphenyl)ethene (11). 


\section{List of Figures}

Figure 1. Deoxygenated model dimers.

Figure 2. HPLC Chromatograms of the reaction mixtures obtained from dimers 2-4 under the pyrolysis conditions $\left(\mathrm{N}_{2} / 400^{\circ} \mathrm{C} / 1 \mathrm{~min}\right)$.

Figure 3. Pyrolytic pathways of $\beta$-ether types of model dimers 1-5.

Figure 4. Quinone methide intermediate and cyclic transition states. 


\begin{tabular}{lllll} 
& & $\mathrm{R}$ & $\mathrm{X}$ & $\mathrm{Y}$ \\
\hline & $\mathbf{2}$ & $\mathrm{H}$ & $\mathrm{OH}$ & $\mathrm{OH}$ \\
& $\mathbf{2}$ & $\mathrm{H}$ & $\mathrm{H}$ & $\mathrm{OH}$ \\
& $\mathbf{3}$ & $\mathrm{OH}$ & $\mathrm{H}$ \\
$\mathrm{OCH}_{3}$ & $\mathbf{5}$ & $\mathrm{CH}_{3}$ & $\mathrm{OH}$ & $\mathrm{OH}$ \\
\hline
\end{tabular}




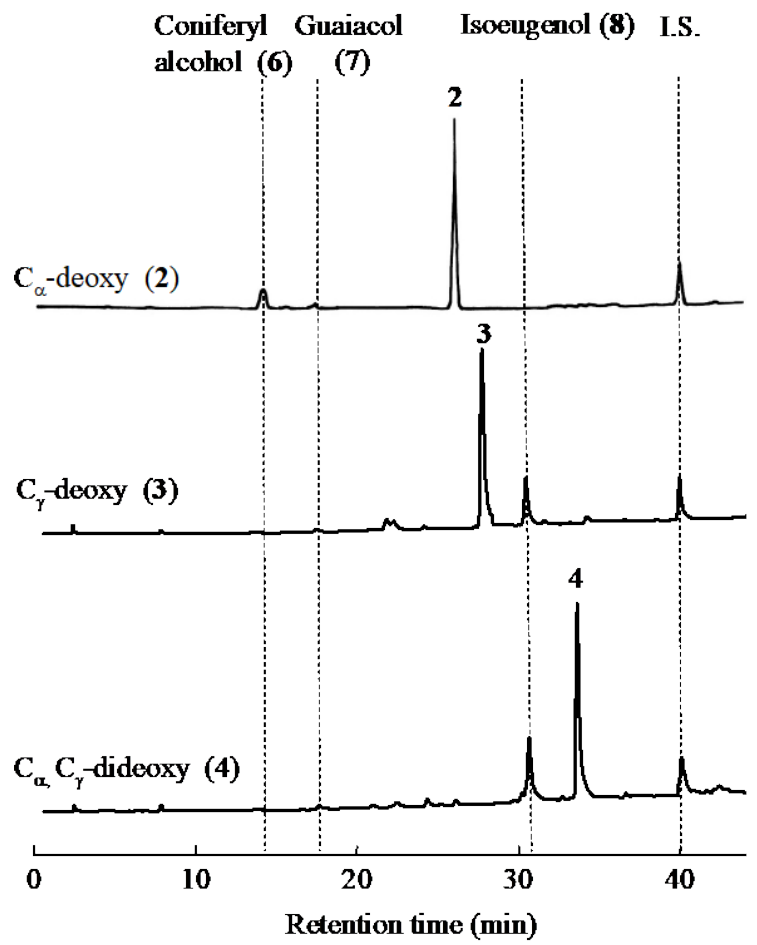




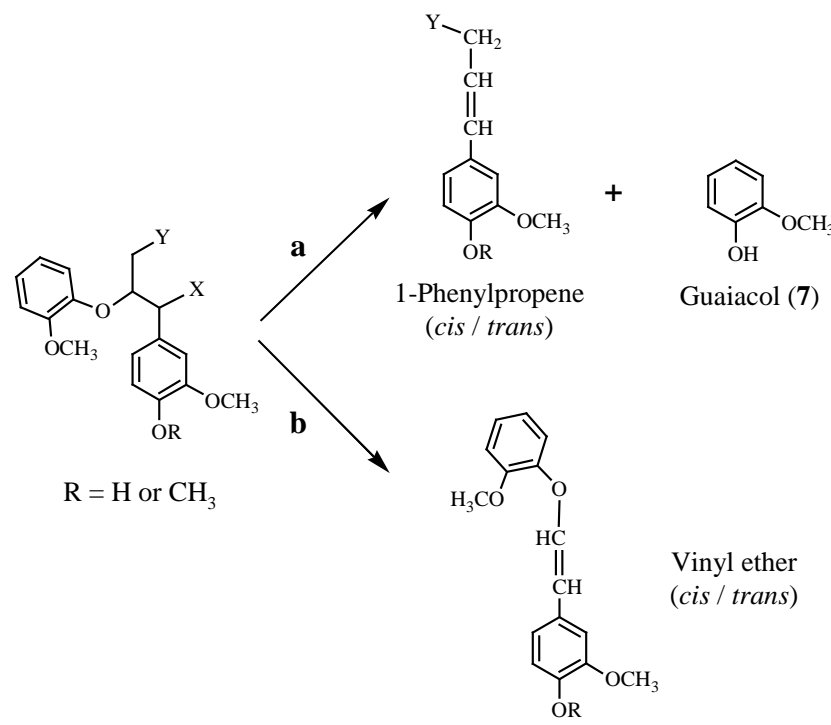




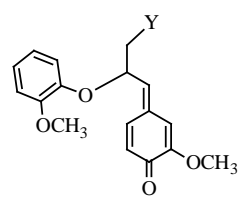

Quinone methide
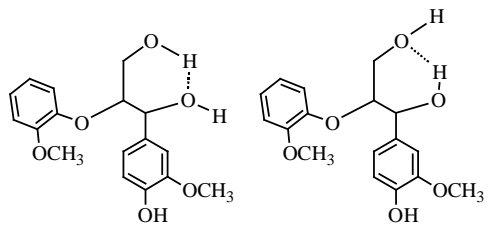

Cyclic transition states 